\title{
Design and realization of English mobile online platform
}

\author{
Lin $\mathrm{Li}^{1, \mathrm{a}}$, Yueguang $\mathrm{Li}^{2, \mathrm{~b}}$ \\ ${ }^{1}$ Gansu Normal University for Nationalities, Hezuo, gansu, 747000, China \\ ${ }^{2}$ Gansu Normal University for Nationalities, Hezuo, gansu, 747000, China \\ aYueguangli7@163.com, bYueguangli7@sohu.com
}

Keywords: Android system; mobile online platform; Design and realization

\begin{abstract}
With the development of digital technology and network technology, mobile learning with mobile computing and digital technology as the foundation, it is a new way of learning, the ongoing promotion and application. In this paper, according to the characteristic of high using rate of the Android system, developed an Android system for English mobile online platform, put forward the principle and system demand of platform, and the test results of the system are given.
\end{abstract}

\section{Introduction}

With the continuous opening of China's economy and society, the popularization and application of campus English is more and more widely. Many people began to realize the importance of learning English. At the same time the development of Internet and communication technology, mobile learning as a new way, due to the characteristics of learning content refining, flexible time. Therefore, based on the Android system, using mobile technology as the foundation[1-3], the development of an English mobile learning platform in this paper, and provides convenience for people' English learning[4-5].

\section{Design and realization of university English mobile learning platform}

\subsection{Analysis of the system functional requirements}

According to the requirements of English learning, the function of the system is divided into front and back two different parts. The onstage mainly includes the user registration, user login, online to recite the words, online test, online search, online translation module; the background includes system management, user management, data management, data category management. The details are as follows:

(1) User management

The system user is divided into learners, educators and administrators in three different roles. The learners can account registration, system login, modify personal information, browse relevant learning resources and enter the forum to review; the educators can browse other related English Resource in addition to learners; administrators manage the system, set on the role of the system, check the information and modify and delete data.

(2) The on-line examination module

The module according to the requirements of university English learning, it is mainly divided into three parts, four grade, six grade, four grade, eight grade and several professional. According to the different role of the system in the module, the number of times test and training in a day are also different. Every day the learners are allowed only one online examination, and the basic difference of ordinary users and members of the user is the membership user can view all of the related resources, and unlimited in exams.

(3) Online to recite the words

Online to recite the words mainly according to our current English test system, divided into English three level, four level, six level, all the way to the professional English eight level. The module has specific requirements for the role every day. 
(4) Online inquiry

This module introduces the function of Google online query, opens to all users.

(5) Online translation

The module also introduces the function of Google online translation, opens to all users.

(6) Video learning

The module mainly provides relevant university English learning video.

\subsection{Architecture of system technical}

This system mainly uses MVC layered design, independent design model, controller and view, each layer also exist the contact, reusable code, and the maintenance of the system in design, so that the system has good scalability, maintainability, reusability and readability. Design client in the view layer using the Android platform itself provides the interface of UI. Control layer using Servlet technology, the specific transfer process is: the client sends a request to the server, the server will transfer request information to Servlet, Servlet will produce the content transmitted to Server, finally, the server will send information to the client end, as shown in figure 1.

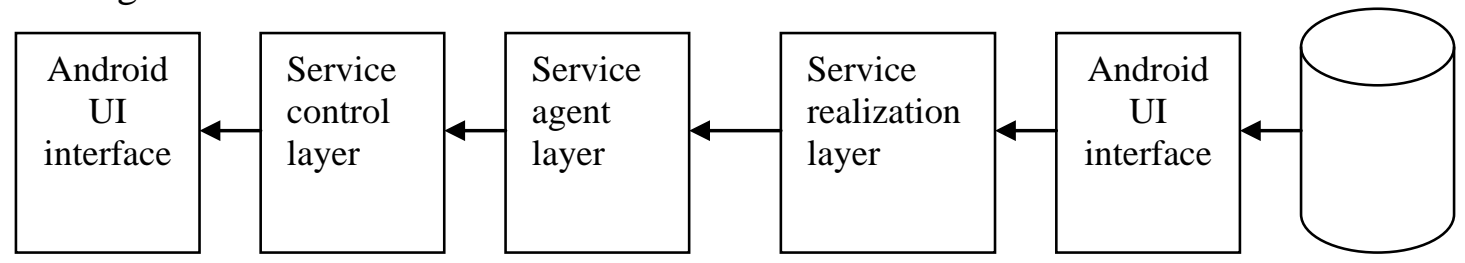

Fig. 1 Architecture of system technical

\subsection{The selection of communication mode}

Communication between the client and the server of the Android system mainly includes the Socket communication based on TCP and UDP; Http protocol based on Http URL Connection; use of URL access network resources; Http Client provided by Apache. For the comparison, we can know that the Socket communication in the server need to deal with mutual exclusion problem ; The client need XML, we select Http Client in the system, because it can send very convenient request and get the HTTP response, thus simplifying the interaction between the server and website.

\subsection{The design of the database}

The database storage using Mysql 2005, driving uses JavaBean technology +JDBC mode. At the same time according to the system's different roles, making two different data tables of the ordinary users and administrator

Table 1 The data table of common user

\begin{tabular}{|c|c|c|c|c|c|}
\hline Number & Field name & Data type & Indexes & Remarks & Whether the air \\
\hline 1 & id & int & PK & Auto increment & NO \\
\hline 2 & userName & varchar & & & NO \\
\hline 3 & password & varchar & & & NO \\
\hline 4 & email & varchar & & & NO \\
\hline 5 & member & int & & $\begin{array}{c}0 \text { ordinary users } \\
1 \text { Members of the users }\end{array}$ & NO \\
\hline 6 & bz & varchar & & & YES \\
\hline
\end{tabular}

Table 2 The data table of embers of the users

\begin{tabular}{|c|c|c|c|c|c|}
\hline Number & Field name & Data type & Indexes & Remarks & Whether the air \\
\hline 1 & id & int & PK & Auto increment & NO \\
\hline 2 & userName & varchar & & & NO \\
\hline 3 & password & varchar & & & NO \\
\hline 4 & bz & varchar & & & YES \\
\hline
\end{tabular}




\section{The realization of university English mobile learning platform}

\subsection{The realization of landing system interface}

In the system, the design of the main interface by using a static text display, therefore, we write it in the XML file and use the linear layout.

\subsection{The implementation of online examination system}

On the realization of the module, the order is the user logs in the system, click each of these features, at the same time into the different functions to learn. While designing the template, must design the database of online examination system, the different English exam exercises are stored in database. Finally, must add the "back" button on each module.

\subsection{Online inquiry}

University English learning query mainly has the word "input, determine", "save", "return" and content display. In the realization of the module, must design the database.

\subsection{The realization of online video module}

According to the function of the system, online video including English movie, English MV, English songs, English video. When the user logs in the system, according to their own need to click on the corresponding learning plate, such as English film. The system will sent corresponding data request to the remote server and play. If the user is an illegal user, the request will fail.

\section{The system performance testing}

Test the module, choose to install the Android system C8650, Y22T, Y210 Huawei type mobile phone to test. At the same time the system select common corresponding delay test as the representative, test the video file playback quality and buffering delay and other factors. The final test results as shown in figure 2. Through the system test, we can see that the system reached the expected target.

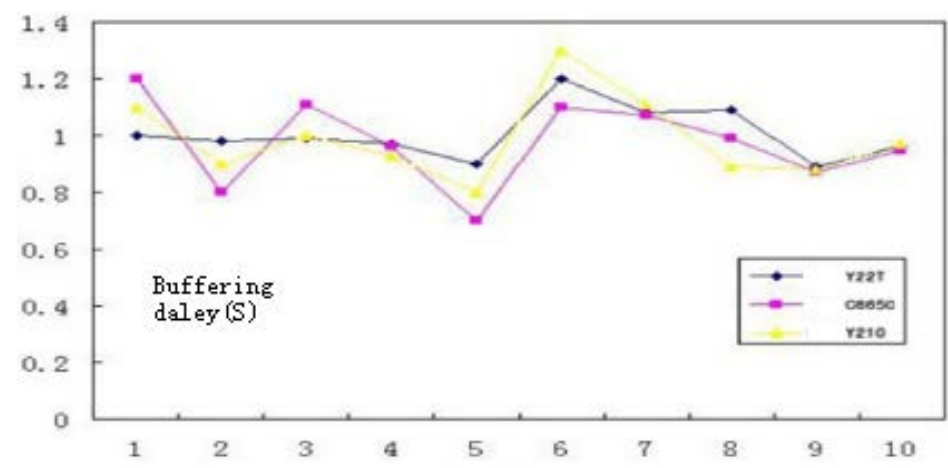

Fig. 2 Online video playback buffer delay curve

\section{Conclusions}

The system uses the C/S structure and Tomcat 6 server, use the servlet to control the server logic. At the same time, the database using mysql2005. The system allows learners to study English, not the time and the place constraint.

\section{Acknowledgment}

This work is supported by Gansu Provincial College graduate tutor of scientific research project (1112-09) and Dean Fund of Gansu Normal College for Nationalities (09-07).

\section{References}

[1] Wang Zhengwei. Prospect of development trend and application of the Android operating system[J]. Computer CD-ROM software and application.2012(18):95-98. 
[2] Zeng Hui. Android system architecture and security mechanisms[J].Information system Engineering. 2012 (01):123-130.

[3] Chen Yiqiang. Android system safety performance[J]. Information systemEngineerin g of of 2011(09):180-182.

[4] Zheng Wei, Qi Youju, Li Yi. Construction and application of mobile learning system in distance education[J]. China distance education. 2012, (03):55-57.

[5] Ding Yongming, Ji Fang Ming. Study and implementation of mobile Android platform[J]. Digital communication world. 2011 0(1): 66 - 687. 